\title{
PEMANFAATAN SOFTWARE GEOGEBRA PADA KOMUNITAS MGMP MATEMATIKA WILAYAH I KABUPATEN ROKAN HULU
}

\author{
Jufri $^{1}$, Annajmi $^{2}$, Hera Deswita ${ }^{3}$ \\ ${ }^{1}$ Teknik Informatika, Universitas Pasir Pengaraian, Indonesia \\ ${ }^{2,3}$ Pendidikan Matematika, Universitas Pasir Pengaraian, Indonesia \\ jufrirokan@gmail.com, annajminajmi86@gmail.com, heraiwit18@gmail.com
}

\begin{abstract}
ABSTRAK
Abstrak: Pemanfaatan TIK dalam pembelajaran matematika dapat dilakukan dengan menggunakan software dimana tujuannya adalah untuk menciptakan pembelajaran matematika yang aktif, kreatif dan menyenangkan. Software Geogebra merupakan program komputer yang dapat dimanfaatkan sebagai media pembelajaran matematika. Berbagai fitur pada Geogebra dapat digunakan untuk mendemontrasikan atau memvisualisasikan konsep-konsep matematis terutama konsep geometri yang bersifat abstrak. Namun sebagian besar guru matematika SMP di Rokan Hulu belum mengetahui cara pemanfaatan software ini. Oleh karena itu dilaksanakan program kemitraan masyarakat melalui komunitas MGMP SMP wilayah I kabupaten Rokan Hulu. Kegiatan ini dilaksankan dalam bentuk pendampingan, pembimbingan dan pelatihan. Evaluasi yang dilakukan selama pelaksanaan pelatihan terlihat peserta pelatihan antusias dalam mengikuti pelatihan, dimana $98,75 \%$ peserta sudah mampu menggunakan Geogebra pada objek-objek dasar geometri. Peserta juga memiliki kemampuan yang baik dalam menggunakan Geogebra pada materi geometri bidang sebesar 96,50\%. Selanjutnya peserta juga mampu dalam menggunakan Geogebra pada bangun ruang yaitu $90 \%$ peserta memiliki kemampuan yang baik dalam menggambarkan bangun ruang dan unsur-unsurnya.
\end{abstract}

Kata Kunci: Pembelajaran Matematika; Software Geogebra.

\begin{abstract}
In following the development of education in the era of Industrial Revolution 4.0 teachers are required to utilize information and communication technology (ICT) in learning,. ICT Utilization in mathematics learning can be done using software where the goal is to create an active, creative and enjoyable math learning. Geogebra Software is a computer program that can be used as a math learning medium. Various features of Geogebra can be used to demonstrate or visualize mathematical concepts especially abstract geometry concepts. However, most of SMP mathematics teachers in Rokan Hulu do not know how to use this software. Therefore implemented Community Partnership program through MGMP community. This activity is carried out in the form of mentoring, coaching and training. Evaluation conducted during training implementation was seen enthusiastic trainees in training, where $98.75 \%$ of participants were already able to use Geogebra on basic objects of geometry such as drawing points, lines through two points, Line segments, parallel lines, and perpendicular lines. Participants also have a good ability to use Geogebra on material geometry fields of 96.50\% include describing the build of quadrilateral and circles, calculating large of angel, calculating the area of polygons and the length of the side of the polygon. Furthermore, participants were also able to use Geogebra on the space geometry that is 90\% of participants have a good ability to draw the space shape og geometry and its elements, also create animations in the formation of nets from space geomtery.
\end{abstract}

Keywords: Mathematic Learning, Software Geogebra 


\section{A. LATAR BELAKANG}

Salah satu mata pelajaran wajib di sekolah, matematika memiliki peranan penting dalam membentuk dan mengembangkan kecakapan berpikir siswa. Hal ini telah termuat dalam Permendiknas No 22 Tahun 2006 bahwa matematika merupakan ilmu universal yang mendasari perkembangan teknologi modern, mempunyai peran penting dalam berbagai disiplin dan memajukan kemampuan berpikir manusia. Hal ini karena matematika bukan sekedar ilmu berhitung, namun lebih dari pada itu, yaitu memberikan keterampilan berpikir tingkat tinggi (Higher Order Thinking Skill/HOTS) termasuk berpikir kritis, kreatif hingga berkomunikasi serta pembentukan karakter (Musfiqi \& Jailani, 2014).

Guru menjadi faktor penentu tercapainya tujuan pembelajaran matematika. Peran guru sangat penting yaitu berkaitan dengan merancang pembelajaran baik menentukan strategi /model pembelajaran, sumber belajar maupun pemanfaatan media pembelajaran (Nurtanto, 2014), (Buchari, 2018), (Syefriyani \& Haji, 2018). Pada pembelajaran konvensional yang menempatkan guru sebagai sumber belajar (teacher centered) sudah menjadi tidak relevan lagi digunakan saat ini. Penerapan kurikulum 2013 saat ini mengharapkan guru agar membuat siswa aktif dalam pembelajaran (students centered). Pembelajaran berbasis aktivitas menggunakan scientific approach, project base learning atau discovery learning adalah cara yang harus dilakukan guru agar terjadi interaksi dua arah baik antara guru-siswa dan antar siswa (Ratnaningsih, 2017), (Sirajuddin, 2017). Selain itu pemanfaatan teknologi dalam pembelajaran juga menjadi suatu keharusan sebagai media pembelajaran khususnya dalam pembelajaran matematika (Putrawangsa \& Hasanah, 2018). Hal yang sama dijelaskan dalam Permendiknas No 65 Tahun 2013 bahwa pemanfaatan Teknologi Informasi dan Komunikasi (TIK) dapat meningkatkan efisiensi dan efektifitas pembelajaran. Lebih lanjut dijelaskan bahwa kesulitan guru dalam penyampaian materi ajar dan kesulitan peserta didik dalam memahami materi bisa diatasi, kesulitankesulitan tersebut akan lebih mudah disampaikan melalui animasi (Alif, Syarief, Sagir, Studi, \& Desain, 2016). Dengan demikian guru ditantang untuk mampu melakukan inovasi dalam proses pembelajaran matematika, salah satu caranya adalah dengan memanfaatkan Teknologi Informasi dan Komunikasi (TIK).

Perubahan dan perkembangan yang terjadi saat ini khususnya pada bidang Teknologi Informasi dan Komunikasi (TIK) terjadi begitu cepat. Saat ini telah hadir berbagai macam kemudahan bagi manusia dalam memenuhi kebutuhannya termasuk peserta didik, yang didukung oleh internet dan dunia digital, berbagai teknologi yang bisa dimanfaat pendidik dan peserta didik dalam meningkatkan kompetensinya, seperti tersedianya berbagai aplikasi untuk belajar matematika, seperti software Geogebra (Fitriasari, 2017), (Panggabean, Sormin, \& Agustina, 2019). Penggunaan 
software dalam pembelajaran matematika dapat memanipulasi berbagai objek matematika. Fungsi Geogebra tersebut sebagai alat-alat geometri untuk mengkonstruksi bangun dan bentuk, sebagai alat geometri dinamis, sebagai alat bantu untuk propabilitas dan analisis data dan pembuat grafik fungsi. Penggunaan software Geogebra juga dapat membantu siswa dalam memahami konsep-konsep geometri yang bersifat abstak, karena software Geogebra tersebut dapat merepresentasikan bangun bangun geometri yang bersifat abstrak.

Permasalahan yang ada pada guru matematika yang tergabung dalam MGMP Matematika Kabupaten Rokan Hulu diantaranya, yaitu

1. Guru matematika SMP di Kabupaten Rokan Hulu sebagian besarnya belum memiliki pengetahuan dan keterampilan dalam menggunakan teknologi terutama multimedia atau software matematika dalam menyajikan pelajaran khususnya geometri.

2. Siswa yang kurang tertarik terhadap pembelajaran matematika yang dilaksanakan guru selalu secara konvensional sehingga menyebabkan rendahnya kemampuan matematika siswa.

3. Rata-rata guru matematika SMP di Kabupaten Rokan Hulu belum menggunakan media elektronik dalam pembelajaran geometri.

4. Beberapa guru hanya menggunakan alat peraga manipulatif yang berbasis hand on activity bahkan kebanyakan guru tidak menggunakan media dalam pembelajaran matematika terutama pada materi geometri.

5. Kebanyakan guru masih menggunakan alat peraga yang dalam hal ini, tentu sangat terbatas jangkauan pemanfaatannya.

Ketua MGMP Matematika Wilayah I Rokan Hulu juga menyampaikan bahwa sebagaian besar guru MGMP matematika SMP Rambah tidak paham menggunakan komputer atau dikenal dengan gaptek (gagap teknologi). Kegiatan MGMP yang sudah pernah dilakukan berkaitan dengan media pembelajaan adalah pelatiahn pembauatan alat peraga dab media berbasis computer. Namun instruktur menyuruh guru untuk mengunduh sendiri software tertentu, dan dijelaskan oleh instruktrur tanpa adanya modul penggunaan software, selain itu juga tidak adanya tindak lanjut atau bimbingan lanjutan setelah pelaksanaan pelatihan atau bimbingan, sehingga menyulitkan guru untuk berkonsultasi.

Berkaitan penjelasan yang telah diuraiankan, oleh karena itu perlu dilakukan pelatihan pemanfaatan software Geogebra dalam pembelajaran matematika. Pemanfaatan media berbasis teknologi komputer dalam pembelajaran matematika sebagai implementasi pembelajaran abad 21 dengan masuknya era revolusi industri 4.0 dalam rangka peningkatan kualitas pembelajaran matematika. Berkaitan dengan itu adapun pelatihan pemanfaatan software Geogebra ini dilakukan pada komunitas MGMP Matematika SMP Wilayah I Kabupaten Rokan Hulu. 


\section{B. METODE PELAKSANAAN}

Kegiatan ini merupakan pelaksanaan pelatihan Pemanfaatan Software Geogebra pada Komunitas MGMP Matematika Wilayah I Kabupaten Rokan Hulu. Kegiatan pelatihan ini meliputi pengenalan software Geogebra, pemanfaatan Geogebra dalam materi Geometri, dan bimbingan kepada guru memanfaatkan Geogebra dalam pembelajaran geometri. Metode kegiatan ini dilaksanakan dengan beberapa tahapan yaitu:

\section{Metode Pendekatan}

Pendekatan dilakukan kepada komunitas MGMP Matematika dalam rangka mengetahui berbagai persoalan yang dihadapi komunitas MGMP Matematika SMP Wilayah I Kab. Rokan Hulu. MGMP Wilayah I tergabung didalamnya 8 kecamatan yaitu, Kecamatan Rambah, Kecamatan Rambah Hilir, Kecamatan Rambah Samo, Kecamatan Bangun Purba, Kecamatan Tambusai, Kecamatan Kepenuhan Hulu, Kecamatan Kepenuhan dan Kecamatan Bonai Darusaalam yang selanjutnya disebut MGMP Matematika SMP Rambah dengan SMMPN 1 Rambah sebagai sekretariat.

\section{Program Kerja}

a. Tahap persiapan, koordinasi pelaksanaan program selama 8 bulan antara tim pengusul, mitra pada tahap ini akan dilakukan persiapan-persiapan yang berhubungan dengan pelaksanaan program, sarana laboratorium komputer atau laptop pribadi dan peralatan dan bahan untuk pelatihan penggunaan Geogebra.

b. Tahap pelaksanaan, pelaksanaan program sesuai dengan kesepakatan bersama antaratim pengusul, komunitas MGMP Matematika SMP Rambah yaitu berupa penyuluhan/pelatihan/workshop antara lain:

1) Pelatihan penggunaan Geogebra sebagai media dalam pembelajaran matematika. Pelatihan ketrampilan ini meliputi pengetahuan dasar tentang Aplikasi Geogebra, pemilihan materi pokok pembelajaran yang dapat memanfaatkan Aplikasi Geogebra, serta merancang pembelajaran yang memanfaatkan Aplikasi Geogebra. Dengan pelatihan ini diharapkan terjadi peningkatan kompetensi guru MGMP matematika SMP Rambah.

2) Pendampingan kepada para peserta pelatihan, dalam rangka: Pemahaman dan aplikasi pengetahuan dan ketrampilan pembelajaranmenggunakan Aplikasi Geogebra. Merancang pembelajaran yang aktif, kreatif, dan menyenangkan denganmemanfaatkan Aplikasi Geogebra mulai dari perencanaan, proses pemilihanmateri, dan penggunaan Aplikasi Geogebra dalam pembelajaran di kelas. 


\section{Monitoring dan Evaluasi}

Monitoring dan evaluasi dilakukan dalam pelaksanaan kegiatan melalui motivasi pada para guru yang sudah dapat menggunakan Aplikasi Geogebra untuk pembelajaran matematika di kelas sehingga bisa konsisten dan tetap bersemangat untuk terus mengembangkan pembelajaran aktif, kreatif, dan menyenangkan.

\section{HASIL DAN PEMBAHASAN}

1. Pelaksanaan Pelatihan

Kegiatan ini dilaksanakan di SMPN 1 Rambah Kabupaten Rokan Hulu yang merupakan sekretariat dari MGMP Matematika Wilayah I Kabupaten Rokan Hulu. Adapun peserta dari pelatihan pemanfaatan software Geogebra ini adalah guru SMP yang ada di 8 (delapan) kecamatan yang tergabung dalam komunitas MGMP Matematika Rambah. Adapun jumlah peserta pelatihan, disajikan pada Tabel 1.

Tabel 1. Data Komunitas MGMP Matematika SMP Rambah

\begin{tabular}{|c|l|c|}
\hline No & \multicolumn{1}{|c|}{ Kecamatan } & Jumlah \\
\hline 1 & Rambah & 15 orang \\
\hline 2 & Rambah Samo & 9 orang \\
\hline 3 & Rambah Hilir & 10 orang \\
\hline 4 & Bangun Purba & 3 orang \\
\hline 5 & Tambusai & 4 orang \\
\hline 6 & Kepenuhan Hulu & 3 orang \\
\hline 7 & Kepenuhan & 3 orang \\
\hline 8 & Bonai Darussalam & 5 orang \\
\hline \multicolumn{2}{|c|}{ Jumlah } & 50 Orang \\
\hline
\end{tabular}

Kegiatan PKM diawali dengan materi pengenalan software Geogebra oleh tim kepada peserta, menu dan tool yang ada pada Geogebra, objekobjek dasar geometri yang meliputi: titik, garis, bangun datar hingga bangun ruang. Suasana kegiatan ini seperti Gambar 1.

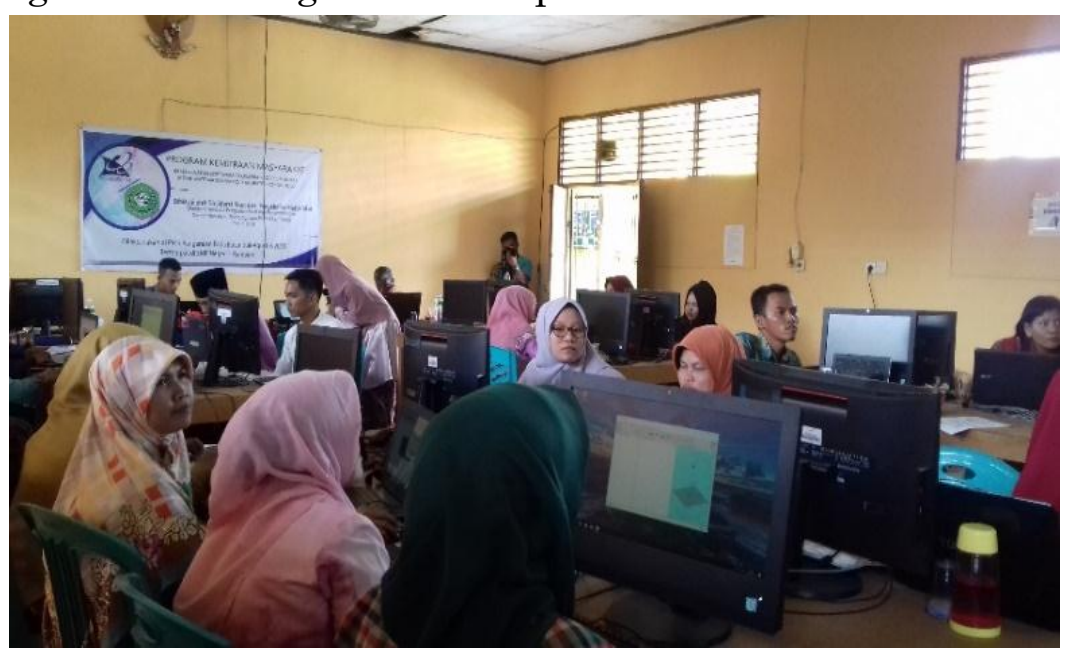

Gambar 1. Materi Geometri Ruang 
Gambar 1 menunjukkan peserta dengan serius memperhatikan materi yang disampaikan oleh pemateri, yaitu mengenai bangun ruang. Disamping itu pemateri dan tim memantau pelaksanaan pelatihan dengan memperhatikan setiap peserta dan memberikan bimbingan dan pendamping kepada peserta yang mengalami kendala dalam menggunakan Geogebra.
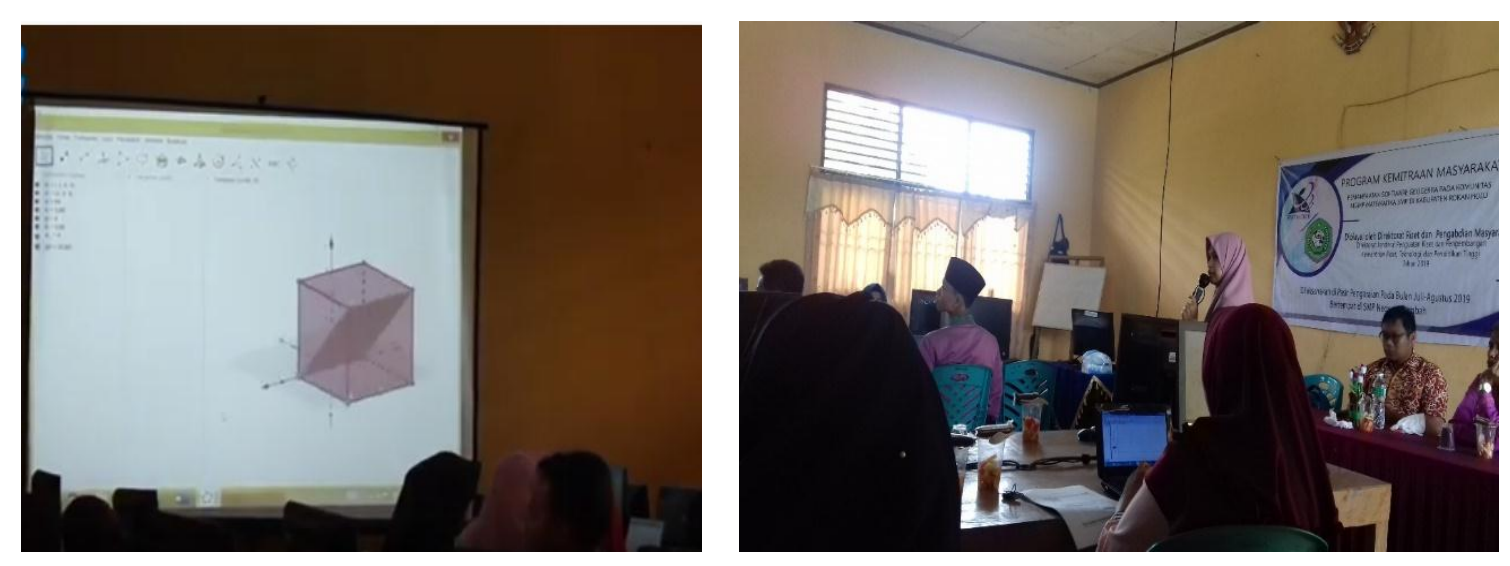

Gambar 2. Tampilan Geometri Ruang pada Geogebra

Gambar 2 menunjukkan contoh pemanfaatan Geogebra pada geometri ruang, yaitu dalam penggambaran kubus beserta unsur-unsurnya oleh pemateri. Peserta juga mencoba menggambar pada laptop masingmasing sesuai Gambar 3 berikut.

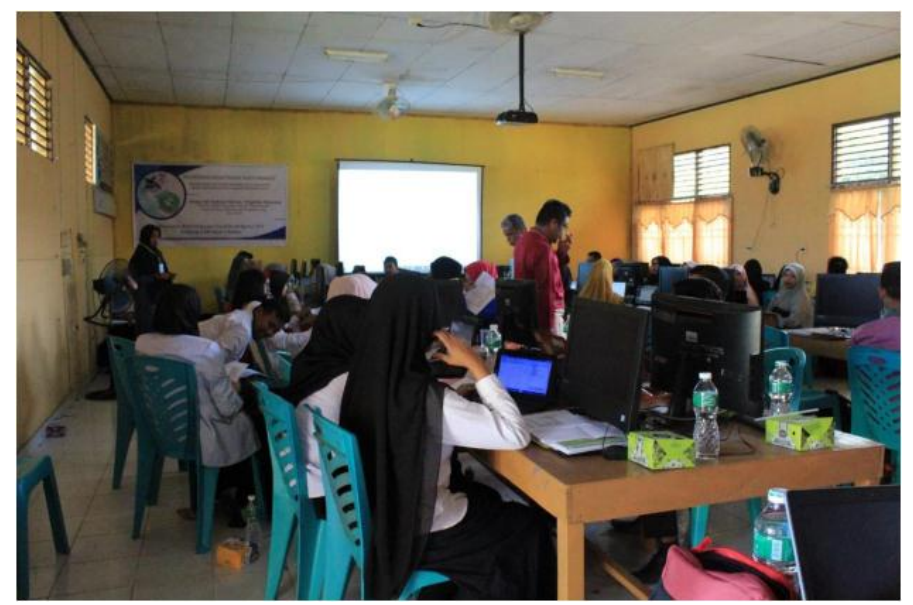

Gambar 3. Peserta Latihan Menggunakan Geogebra

Gambar 3 menunjukkan peserta melakukan praktek menggunakan Geogebra berdasarkan materi yang disampaikan pemateri. Pemateri memantau peserta dalam menggunakan Geogebra sebagai latihan.

\section{Evaluasi}

Evaluasi kegiatan ini dilakukan untuk mengetahui keberhasilan dalam pelaksnaan pelatihan. Evaluasi dilakukan selama proses pelatihan berlangsung dan diakhir kegiatan pelatihan dengan menyebarkan angket kepada peserta pelatihan. Evaluasi proses merupakan untuk mengetahui 
ketercapaian tujuan pelatihan dengan melakukan observasi dan evaluasi penyelenggaraan dan pemahaman peserta dilakukan dengan memberikan angket.

\section{a. Evaluasi Selama Proses Pelatihan}

Evaluasi proses selama pelaksanaan pelatihan meliputi, keterlibatan dan kemampuan peserta dalam setiap tahap pelatihan. Peserta diharapkan mampu menggunakan Geogebra dalam pembelajaran matematika khsuusnya materi geometri, persamaan dan fungsi. Indikator keberhasilan pelatihan dilihat dari keterampilan dan kemampuan peserta dalam menggunakan Geogebra pada materi-materi yang disampaikan. Peserta terlihat sebagian besar mampu menggunakan Geogebra dalam membuat gambar segmen garis, garis melalui dua titik, bangun datar, menghitung sudut dan menggambarkan bangun ruang beserta unsur-unsurnya.

\section{b. Evaluasi Pasca Pelatihan}

Evaluasi pasca pelatihan dilakukan dengan memberikan angket kepada peserta pelatihan dengan beberapa pernyataan. Keberhasilan kegiatan pelatihan dilihat dari pengetahuan dan kemampuan peserta dalam menggunakan Geogebra dalam pembelajaran matematika pada materi materi tertentu dan tindak lanjut dari pelatihan yang telah dilakukan. Berikut disajikan data kemampuan guru dalam menggunakan Geogebra pada Tabel 2.

Tabel 2. Hasil Angket Pasca Pelatihan

\begin{tabular}{clc}
\hline No & \multicolumn{1}{c}{ Pernyataan } & $\begin{array}{c}\text { Tingkat } \\
\text { Keberhasilan }\end{array}$ \\
\hline 1 & $\begin{array}{l}\text { Mampu mengenali fungsi-fungsi dari tool yang ada } \\
\text { pada Geogebra }\end{array}$ & $97 \%$ \\
\hline 2 & Mampu membuat titik dan segmen garis & $100 \%$ \\
\hline 3 & Mampu membuat garis melalui dua titik & $100 \%$ \\
\hline 4 & Mampu membuat garis sejajar, garis tegak lurus & $98 \%$ \\
\hline 5 & Mampu membuat poligon sebarang & $98 \%$ \\
\hline 6 & Mampu membuat poligon beraturan & $98 \%$ \\
\hline 7 & Mampu membuat segiempat & $95 \%$ \\
\hline 8 & $\begin{array}{l}\text { Mampu mengukur sudut, panjang sisi dan membuat } \\
\text { sudut dan panjang dengan besaran tertentu }\end{array}$ & $95 \%$ \\
\hline 9 & Mampu membuat bangun ruang & $95 \%$ \\
\hline 10 & $\begin{array}{l}\text { Mampu membuat animasi jaring-jaring barung } \\
\text { ruang }\end{array}$ & $85 \%$ \\
\hline 11 & $\begin{array}{l}\text { Mampu menggambarkan unsur-unsur bangun } \\
\text { ruang }\end{array}$ & $90 \%$ \\
\hline
\end{tabular}

Tabel 2 memperlihatkan kemampuan guru dalam menggunakan Geogebra, dapat dilihat bahwa guru sudah memiliki kemampuan yang cukup baik dalam memanfaatkan Geogebra dalam pembelajaran 
matematika, khususnya objek-objek dasar pada geometri, baik pada bangun datar maupun bangun ruang.

\section{SIMPULAN DAN SARAN}

Berdasarkan hasil analisis data dan hasil evaluasi dari pelaksanaan kegiatan PKM ini dapat disimpulkan bahwa adanya peningkatan kemampuan dan keterampilan guru dalam menggunakan Geogebra pada materi geometri dasar, geometri bidang dan geometri ruang. Secara keseluruhan diperoleh bahwa $98,75 \%$ peserta sudah mampu menggunakan Geogebra pada objek-objek dasar geometri seperti menggambar titik, garis melalui dua titik, segmen garis, garis sejajar, dan garis tegak lurus. Peserta juga memiliki kemampuan yang baik dalam menggunakan Geogebra pada materi geometri bidang (poligon) sebesar 96,50\% yang meliputi menggambarkan bangun segiempat dan lingkaran, menghitung besar sudut, menghitung luas poligon dan panjang sisi dari poligon. Selanjutnya peserta juga mampu dalam menggunakan Geogebra pada bangun ruang yaitu 90\% peserta memiliki kemampuan yang baik dalam menggambarkan bangun ruang dan unsur-unsurnya, juga membuat animasi dalam pembentukan jaring-jaring dari bangun ruang.

Berkaitan dengan itu disarankan kepada pihak sekolah untuk mendukung guru memanfaatkan TIK seperti aplikasi Geogebra dalam pembelajaran matematika sebagai media pembelajaran dengan menyediakan fasilitas pendukung. Pihak-pihak lain untuk dapat melakukan kegiatan pelatihan-pelatihan serupa dalam rangka meningkatkan kompetensi guru memanfaatkan media berbasis teknologi khususnya software Geogebra.

\section{UCAPAN TERIMA KASIH}

Tim Abdimas Program Kemitraan Masyarakat (PKM) mengucapkan terima kasih kepada:

1. Direktorat Riset dan Pengabdian Masyarakat (DRPM) Direktorat Jenderal Penguatan Riset dan Pengembangan yang telah mendanai kegiatan pengabdian ini sehingga terlaksana dengan sukses;

2. Lembaga Penelitian dan Pengabdian Masyarakat (LPPM) Universitas Pasir Pengaraian;

3. Dinas Pendidikan Pemuda dan Olahraga Kabupaten Rokan Hulu;

4. Komunitas MGMP Matematika Wilayah I Kabupaten Rokan Hulu selaku mitra pelaksanaan PKM ini;

5. SMPN 1 Rambah sebagai tempat pelaksanaan kegiatan pelatihan, sehingga terlaksanakan kegiatan PKM dengan lancar dan sukses.

\section{DAFTAR RUJUKAN}

Alif, C., Syarief, A., Sagir, I. S., Studi, P., \& Desain, M. (2016). Rancangan Animasi Penyuluhan Bagi Calon Guru Yang Akan Mengajar. Serat Rupa Journal of Design, 1(2), 317-327.

Buchari, A. (2018). Peran Guru Dalam Pengelolaan Pembelajaran. Jurnal Ilmiah 
Iqra', 12(2), 106. https://doi.org/10.30984/jii.v12i2.897

Fitriasari, P. (2017). Pemanfaatan Software Geogebra Dalam Pembelajaran Matematika. Jurnal Pendidikan Matematika RAFA, 3(1), 57-69. https://doi.org/10.19109/jpmrafa.v3i1.1441

Musfiqi, S., \& Jailani. (2014). Pengembangan Bahan Ajar Matematika yang Berorientasi pada Karakter dan Higher Order Thinking Skill (HOTS) Developing Mathematics Instructional Materials Oriented to Character and Higher Order Thinking Skill (Hots). PYTHAGORAS, 9(1), 45-59.

Nurtanto, M. (2014). Mengembangkan Kompetensi Profesionalisme Guru Dalam Menyiapkan Pembelajaran Yang Bermutu. jJrnal Pendidikan, (10), 553-565.

Panggabean, N. S., Sormin, M. A., \& Agustina, L. (2019). Workshop Pemanfaatan Media Pembelajaran Geogebra Untuk Meningkatkan Kompetensi Guru Matematika. Martabe: Jurnal Pengabdian Kepada Masyarakat, 2(1), 40. https://doi.org/10.31604/jpm.v2i1.40-44

Putrawangsa, S., \& Hasanah, U. (2018). Integrasi Teknologi Digital Dalam Pembelajaran Di Era Industri 4.0 Kajian dari Perspektif Pembelajaran Matematika. Jurnal Tatsqif, 16(1), 42-54.

Ratnaningsih, S. (2017). Scientific Approach Of 2013 Curriculum: Teachers Implementation In English Language Teaching. English Review: Journal of English Education, 6(1), 33. https://doi.org/10.25134/erjee.v6i1.792

Sirajuddin, S. (2017). Pengembangan Perangkat Pembelajaran Matematika Dengan Kombinasi Pendekatan Matematika Realistik Dan Scientific Pada Siswa Kelas VII SMP. Jurnal Teori Dan Aplikasi Matematika (JTAM), 1(1), 60. https://doi.org/10.31764/jtam.v1i1.316

Syefriyani, D., \& Haji, S. (2018). Penerapan Lesson Study Untuk Meningkatkan Self-Concept Mahasiswa Pada Mata Kuliah Konsep Dasar Matematika. Jurnal Teori Dan Aplikasi Matematika (JTAM), 2(1), 101. https://doi.org/10.31764/jtam.v2i1.388 